\title{
Diagnósticos locais do Plano de Ações Articuladas: uma análise de sua confiabilidade
}

\author{
Local diagnoses of Articulated Action Plan: an analysis of their reliability
}
Diagnósticos locales del "Plan de Acciones Articuladas": un análisis de su confiabilidad

\author{
DONALDO BELLO DE SOUZA* \\ AlZIRA BATALHA ALCÂNTARA** \\ MARIA CELI CHAVES VASCONCELOS ${ }^{* * *}$
}

\begin{abstract}
RESUMO - O artigo visa à análise da confiabilidade da diagnose do PAR no Estado do Rio de Janeiro, tomando por base dados oficiais de sua implantação em 90 (98\%) dos seus 92 Municípios, relativos ao quadriênio 2007-2010, de modo a avaliar a possibilidade de estarem refletindo desafios postos à realidade educacional deste território. Do ponto de vista interno aos mecanismos diagnósticos do PAR, constata a existência de inconsistências e incoerências vinculadas aos indicadores e critérios empregados, enquanto que do ponto de vista externo, relativo à sua elaboração local, hipotetisa sobre possíveis desvios de sua finalidade original. Em consequência, postula que os dados fornecidos por esses diagnósticos são duvidosos, pouco contribuindo para o conhecimento da realidade educacional no Estado.

Palavras-chave - Plano de Desenvolvimento da Educação. Planos de Ações Articuladas. Descentralização da Educação. Municipalização da Educação. Rio de Janeiro.
\end{abstract}

\begin{abstract}
This article seeks to analyse the reliability of the PAR diagnosis in the State of Rio de Janeiro, on the basis of official data since its implementation in 90 (98\%) of its 92 municipalities, covering the period between 2007 and 2010, so as to evaluate how reliable they are in reflecting challenges found in the educational reality in this State. Inconsistencies related to indicators and criteria employed are detected in the PAR diagnosis mechanisms, while a hypothesis is raised regarding possible deviations from the PAR original purpose. As a result, the article postulates that the data supplied by such diagnoses are disputable and scarcely contribute to a knowledge of the educational reality of the State.
\end{abstract}

Keywords - Education Development Plan. Articulated Action Plans. Decentralization of education. Transfer of education to municipalities. Rio de Janeiro.

RESUMEN - El artículo tiene como objetivo analizar la confiabilidad del diagnóstico del PAR en El Estado de Rio de Janeiro, basado en datos oficiales de su implementación en 90 (98\%) de sus 92 municipios correspondiente cuatrienio 2007-2010, con el fin de evaluar la posibilidad de estar reflejando los desafíos puestos a la realidad educativa de este territorio. Del punto de vista interno a los mecanismos de diagnóstico del PAR, se constata que la existencia de inconsistencias y contradicciones están vinculados a los indicadores y criterios utilizados; mientras que el punto de vista externo, relativo a su elaboración local, se plantea la hipótesis de posibles desviaciones de su propósito original. Por tanto se postula que los datos proporcionados por estos diagnósticos son dudosos, contribuyendo poco al conocimiento de la realidad educacional del Estado.

Palabras clave - Plan de Desarrollo Educativo. Planes de Acciones Articulados. Descentralización de la educación. Municipalización de la educación. Río de Janeiro.

* Doutor em Educação pela Universidade Federal do Rio de Janeiro (Rio de Janeiro, RJ, Brasil) e Professor na Universidade do Estado do Rio de Janeiro (Rio de Janeiro, RJ, Brasil). E-mail: < donaldosouza@hotmail.com>.

** Doutora em Educação pela Universidade Federal Fluminense (Rio de Janeiro, RJ, Brasil) e Professora na Faculdade de Educação da Baixada Fluminense e Universidade do Estado do Rio de Janeiro (Rio de Janeiro, RJ, Brasil).E-mail: <alzirabatalha@hotmail.com>.

*** Doutora em Educação pela Pontifícia Universidade Católica do Rio de Janeiro (Rio de Janeiro, RJ, Brasil) e Professora na Universidade Católica de Petrópolis (Petrópolis, RJ, Brasil).E-mail:<maria.celi@ucp.br>. 


\section{INTRODUÇÃO}

Em 24 de abril de 2007 o governo federal instituiu, por meio do Decreto no 6.094 (BRASIL, 2007a), o Plano de Desenvolvimento da Educação (PDE), elaborado pelo Ministério da Educação (MEC), de caráter executivo, organizado a partir de quatro eixos norteadores, a saber: Educação Básica, Educação Superior, Educação Profissional e Alfabetização, apresentado com a missão de identificar e solucionar problemas que afetam, prioritariamente, a Educação Básica no país, visando a sua qualidade, em todos os níveis e modalidades, no prazo de quinze anos (BRASIL.MEC, 2007).

Dentre o conjunto de ações previstas para a consecução do PDE - que inicialmente contou com cerca de 27 programas/diretrizes para, logo em seguida, por sedimentação proporcionada pelo próprio MEC, vir a compreender mais de 50 dispositivos -, o governo federal elaborou dois planos imbricados: de um lado, o Plano de Metas Compromisso Todos pela Educação e, de outro, o Plano de Ações Articuladas (PAR), também objetos do Decreto no 6.094/2007 (BRASIL, 2007a). Mais recentemente, por intermédio da Lei no 12.695, de 25 de julho de 2012 (BRASIL, 2012), o PAR veio a ser elevado à condição de política nacional desvinculada do Plano de Metas Compromisso.

No Estado do Rio de Janeiro, o PDE implicará repercussão municipal num contexto impactado pela regulamentação do Sistema Estadual de Ensino, instituído pela Lei Estadual no 4.528, de 28 de março de 2005 (RIO DE JANEIRO, 2005) que, entre outros aspectos, deflagrou a extinção da oferta estadual da Educação Infantil e intentou, igualmente, efetuá-la em relação aos anos iniciais do Ensino Fundamental.

Assim, o presente artigo visa à análise da confiabilidade dos diagnósticos do PAR no Estado do Rio de Janeiro, tomando por referência dados oficiais de sua implantação em 90 (98\%) dos seus 92 Municípios, relativos ao quadriênio 2007-2010, de modo a avaliar a possibilidade de estarem fidedignamente refletindo desafios postos à realidade educacional deste território, identificando eventuais fragilidades na sua formulação. $\mathrm{Na}$ seção que segue a esta, estabelecem-se algumas considerações sobre as relações entre federalismo, descentralização e sistemas de ensino para, em seguida, pontuar as formas de organização da educação municipal previstas a partir da promulgação da Constituição Federal (CF) de 1988. Na quarta seção é traçado um breve cenário da municipalização da educação no Estado do Rio de Janeiro, incluindo um balanço das suas matrículas na Educação Infantil e no Ensino Fundamental. Após, realiza-se um exame crítico sobre o PDE e os seus pilares operacionais - o Plano de Metas Compromisso Todos pela Educação e o PAR -, tomando por base, de um lado, a legislação correlata e, de outro, a literatura acadêmica pertinente. Na penúltima seção problematizam-se determinadas fragilidades reveladas pelos critérios federais que avaliaram os indicadores do PAR neste, com base nos dados disponibilizados pelo Sistema Integrado de Monitoramento, Execução e Controle do Ministério da Educação (Simec). Por fim, quando na conclusão, buscase estabelecer as relações necessárias à reflexão sobre as possibilidades e limites de os diagnósticos realizados por meio do PAR contribuírem, de fato, para o conhecimento dos desafios postos à educação municipal no Estado do Rio de Janeiro.

\section{FEDERALISMO, DESCENTRALIZAÇÃO E SISTEMAS DE ENSINO}

Conforme discutido por Souza e Faria (2003), as reflexões acerca dos ideais descentralizadores têm transitado entre uma visão relativamente otimista do papel do Estado neste processo e o protagonismo acentuado da sociedade civil, entendidos como espaços separados e opostos, ocorrendo identificações imediatas da democracia com toda e qualquer ação descentralizadora da prestação de serviços públicos pelo Estado, em contraposição às concepções que associam as formas centralizadas de sua gestão ao autoritarismo e à ineficácia estatais.

Todavia, há o reconhecimento de que o fenômeno político da descentralização depende, sobremaneira, do contexto histórico e sociopolítico de cada realidade a que se relaciona, definidor, portanto, de seu grau e amplitude (VENEZIANO, s.d.). Nesta perspectiva, a viabilidade da descentralização de políticas públicas na área social se encontra mais dependente da natureza dos vínculos estabelecidos entre as burocracias públicas e as possibilidades de controle e acompanhamento por parte da sociedade, do que propriamente em relação à estrita esfera governamental, responsável pela promoção e execução de tais serviços (ABREU; SARI, 1999; MARTINS, 2001). A qualidade democrática desses vínculos, tanto no âmbito do relacionamento entre os entes federados, como na esfera do binômio EstadoSociedade, é que irá implicar, portanto, uma maior partilha de poderes (descentralização) ou, ao revés, a ocorrência de um simples deslocamento de competências, atribuições e encargos (desconcentração) (ABREU, 2002; CASSASUS, 1995; SOUZA; CARVALHO, 1999).

No Brasil, ao final dos idos de 1980, o processo de redemocratização do País irá favorecer a recuperação das bases do Estado federativo brasileiro (eleições diretas e descentralização fiscal), com forte impacto sobre o processo de descentralização das políticas sociais (ARRETCHE, 1999). Ainda de acordo com Arretche 
(2002a; 2002b), a recuperação das bases federalistas do Brasil, cujo marco jurídico inicial consistiu na CF/1988 (BRASIL, 1988), implicou redistribuição da autoridade política entre os entes federados, a partir deste momento também incluindo os Municípios como atores políticos autônomos, significando, entre outras dimensões, a possibilidade de os Estados, Distrito Federal e agora os Municípios, ao lado da União, formularem e implementarem suas próprias políticas.

Tal arranjo político veio a refletir-se no ordenamento dos sistemas de ensino do País, conforme inicialmente definido no art. 211 da CF/1988 (BRASIL, 1988) e, logo após, no art. $8^{\circ}$ da Ldben no 9.394, de 20 de dezembro de 1996 (BRASIL, 1996), pressupondo a estruturação e o funcionamento autônomo, porém cooperativo, dos sistemas de ensino federal, estaduais, distrital e municipais.

Para Cury (2004, p. 15), a noção de sistema implica considerar tanto a "unidade e a multiplicidade em vista de uma finalidade comum quanto o modo como se procura articular tais elementos", o que corrobora a clássica definição de Saviani (1996, p. 80) de que "Sistema é a unidade de vários elementos intencionalmente reunidos, de modo a formar um conjunto coerente e operante [grifos do original]", com "organização sob normas próprias (o que lhe confere um elevado grau de autonomia) e comuns (isto é, que obrigam a todos os seus integrantes)" (SAVIANI, 1999, p. 121). No campo educacional, a noção de sistema daí derivada levará à compreensão, de acordo com o Parecer CNE/CEB no 30, de 12 de setembro de 2000 (BRASIL.CNE.CEB, 2000), de relatoria do então conselheiro Carlos Roberto Jamil Cury, que sistema de ensino consiste no "conjunto de campos de competências e atribuições voltadas para o desenvolvimento da educação escolar que se materializam em instituições, órgãos executivos e normativos, recursos e meios articulados pelo poder público competente, abertos ao regime de colaboração e respeitadas as normas gerais vigentes".

Ou seja, no âmbito das suas respectivas esferas federadas, tal organização sistêmica significa que cada sistema goza de autonomia própria e, a um só tempo, em função do fato de serem interdependentes, devem atuar em regime de colaboração. Neste sentido, conforme enfatiza Cury (2010), ao final dos idos de 1980 passou-se a enfrentar no País o desafio do não extremismo dos pólos característicos do pacto federalista que pode conduzir, de um lado - pela homogeneização das diferenças nacionais -, à revogação da autonomia entre os entes federados, acarretando maior centralização do poder político, e de outro, à exacerbação da autonomia desses entes, no limite da soberania, conduzindo "à dispersão anárquica" (CURY, 2010, p. 24). O desafio consistiria, pois, na afirmação da autonomia dos governos subnacionais e, a um só tempo, na garantia de cumprimento da função coordenadora da União (DOURADO, 2013), o que pode levar à constituição de um Sistema Nacional de Educação, entendendo-o como "unidade dos vários aspectos ou serviços educacionais mobilizados por determinado país, intencionalmente reunidos de modo a formar um conjunto coerente que opera eficazmente no processo de educação da população do referido país" (SAVIANI, 2010, p. 381).

Mais recentemente, com a promulgação da Emenda Constitucional (EC) no 59, de 11 de novembro de 2009 (BRASIL, 2009), que altera o art. 214 da CF/1988 (BRASIL, 1988), foi introduzido o conceito de "sistema nacional de educação em regime de colaboração" que, avançando na perspectiva do funcionamento articulado e cooperativo dos sistemas de ensino dos entes federados, agora passa a considerar o papel de um Plano Nacional de Educação (PNE), de duração decenal, como mediador desse processo.

\section{ORGANIZAÇÃo DA EDUCAÇÃo MUNICIPAL Pós-CF/1988}

De modo anterior à $\mathrm{CF} / 1988$ (BRASIL, 1988), no início da década de 1960, políticas de descentralização da gestão do ensino já haviam repercutido no âmbito estadual, uma vez que, com a promulgação da Lei ${ }^{\circ}$ 4.024, de 20 de dezembro de 1961 (BRASIL, 1961), foram criados os Sistemas Estaduais de Ensino, incluídos os seus respectivos Conselhos Estaduais de Educação (CEEs). A lei subsequente, Lei no ${ }^{-}$5.692, de 11 de agosto de 1971 (BRASIL, 1971), viria a ratificar essa política em suas Disposições Transitórias (art. 71) quando se refere aos Municípios, aludindo aos Conselhos Municipais de Educação (CMEs) a delegação de parte das atribuições dos CEEs, isto em função da existência de condições locais para tanto. Assim, nesse momento, surge a primeira menção legal à possibilidade de normatização da educação em âmbito municipal, uma vez que a Lei no 5.692/1971 abria a possibilidade de os Municípios contarem com um órgão próprio de planejamento da educação, o CME, estratégico para a configuração local da educação, quer pelas atribuições e funções/competências que institucionalmente desempenha, quer em decorrência da possibilidade de facultar a participação sociopolítica local.

Do ponto de vista jurídico, a situação acima permaneceria inalterada até a CF/1988 (BRASIL, 1988), quando, conforme anteriormente sinalizado, os Municípios seriam elevados à condição de entes autônomos federados, sendo facultada, no exercício da sua autonomia, a criação dos seus sistemas de ensino. Oito anos mais tarde, esta previsão da $\mathrm{CF} / 1988$ viria a ser regulamentada pela Ldben no 9.394/1996 (BRASIL, 1996), também se 
consolidando em torno de determinações relativas às incumbências legais educacionais dos Municípios. Assim, de acordo com essa Ldben, os Municípios passaram a possuir a incumbência, entre outras, de "organizar, manter e desenvolver os órgãos e instituições oficiais dos seus sistemas de ensino, integrando-os às políticas e planos educacionais da União e dos Estados" (BRASIL, 1996, art. 11, I) ou, no caso de não optarem pela constituição dos seus próprios sistemas, integrarem-se "ao sistema estadual de ensino ou compor com ele um sistema único de educação básica" (BRASIL, 1996, art. 11, parágrafo único).

A primeira modalidade, considerada por Cury (2004, p. 20) como "a base de um sistema municipal de ensino, próprio e autônomo", refere-se à criação propriamente dita de um Sistema Municipal de Ensino próprio, abrangendo: i) as instituições escolares de Educação Básica - de Educação Infantil, de Ensino Fundamental e de Ensino Médio (caso haja) públicas - e privadas de Educação Infantil; ii) os órgãos de administração central da educação municipal - a Secretaria Municipal de Educação (SME), instância predominantemente executiva, que exerce funções de coordenação, supervisão, articulação e implementação das políticas e ações educacionais, e o CME, de caráter preponderantemente normativo, também com funções deliberativa, consultiva, fiscalizadora, mobilizadora e propositiva (SOUZA, DUARTE; OLIVEIRA, 2013 -; assim como o iii) Plano Municipal de Educação (PME) e o conjunto de normas complementares emanadas por estes órgãos (SARI; MARTINS; CASTIGLIONI, 2006).

Já a opção de integração ao Sistema Estadual de Ensino implica considerar que ao invés de o CME vir a exercer sua competência normativa, esta passa a ser prerrogativa do Conselho Estadual de Educação (CCE). Por seu turno, a composição com o Sistema Estadual de Ensino de um Sistema Único de Educação Básica remete à condição de que a administração das instituições públicas de ensino seja realizada conjuntamente pelo Estado e Município (SARI; MARTINS; CASTIGLIONI, 2006).

Ainda de acordo com Sari, Martins e Castiglioni (2006, p. 93), "a maioria dos municípios brasileiros encontra-se em uma situação que poderia ser ainda considerada de transição entre o regime anterior (Lei $\mathrm{n}^{\mathrm{o}}$ $5.692 / 71)$ e as possibilidades previstas na atual legislação", isto pelo fato de não terem constituído os seus próprios Sistemas Municipais de Ensino e, em consequência, ainda encontrarem-se normativamente vinculados ao Sistema Estadual de Ensino, não significando, contudo, existência da integração aludida pela Ldben no 9.394/1996 (BRASIL, 1996).

De fato, segundo a Pesquisa de Informações Básicas Municipais (Munic), realizada pelo Instituto Brasileiro de Geografia e Estatística (IBGE), relativa ao ano de 2011 (BRASIL.IBGE, 2012), apenas 2.048 (36,8\%) Municípios, de um total, à época, de 5.565, possuíam sistema de ensino próprios, estando o restante $(63,2 \%)$ vinculado aos respectivos sistemas estaduais. Na Região Sudeste, do total de 1.668 localidades, 485 (29\%) declararam possuir Sistema Municipal de Ensino. No caso do Estado do Rio de Janeiro a quase totalidade dos seus Municípios informou ter constituído os seus respectivos sistemas de ensino - $80(87 \%)$ do total de 92 localidades -, sendo que apenas $12(13 \%)$ o possuíam vinculado (e não integrado) ao Sistema Estadual de Ensino.

\section{MUNICIPALIZAÇÃO DO ENSINO NO ESTADO DO RIO DE JANEIRO}

Conforme destacado por Souza e Vasconcelos (2013), em que pese o fato de ter sido a partir da CF/1988 que as Leis Orgânicas Municipais (LOMs) passaram a prever a implantação dos sistemas de educação, acompanhados dentre outras instâncias, de seus respectivos CMEs, em alguns Municípios fluminenses esses conselhos já atuavam como órgãos consultores e normativos desde a década de 1970, principalmente aqueles que possuíam delegação de competências do CEE. Tal delegação,

\footnotetext{
posteriormente denominada 'transferência de responsabilidades', dava-se, entre outros motivos, pela impossibilidade de as Secretarias Estaduais de Educação (SEE), com a crescente ampliação das redes de ensino pública e privada nos municípios, atenderem às demandas locais por regulamentação, supervisão e fiscalização, especialmente do ensino fundamental, permitindo que os Municípios que possuíssem condições estruturais assumissem tais responsabilidades (SOUZA; VASCONCELOS, 2013, p. 133).
}

Ao final dos idos de 1980, por meio da Resolução da SEE nº 1.411, de 03 de dezembro de 1987 (RIO DE JANEIRO.SEE, 1987) - alterada pela Resolução SEE no 1.488 , de 08 de março de 1989 (RIO DE JANEIRO. SEE, 1989) -, foi instituído o Programa Estadual de Municipalização do Ensino de Primeiro Grau (Promurj), voltado à municipalização do atual Ensino Fundamental no Estado, "entendendo-o como um processo gradativo que deveria respeitar a autonomia municipal, já que ocorreria no âmbito de dois poderes públicos autônomos" (SOUZA; VASCONCELOS, 2012, p. 35). Assim, o Promurj previa o estabelecimento de um convênio entre o Estado do Rio de Janeiro, por intermédio de sua SEE, e o Município interessado, fixando, com isto, as competências de cada uma das partes conveniadas. 
Com a Ldben no 9.394/96 (BRASIL, 1996), não mais se tratava de a SEE-RJ delegar competências aos Municípios, mas sim da concretização da implantação de seus respectivos Sistemas Municipais de Ensino, incluídos os CME a serem criados por lei municipal própria. A partir daí, a orientação do CEE-RJ veio a ser no sentido de que os Municípios deveriam constituir os seus sistemas, "conceituados como o conjunto de instituições de ensino e de educação sob a jurisdição do Município naquilo que a lei preconiza, para que lhes fosse 'reconhecida' a competência de sistema próprio e para que passassem a atuar plenamente em suas atribuições, até então realizadas pelo Estado" (VASCONCELOS, 2003, p. 114), dando prosseguimento ao processo de liberação do Estado para com a oferta das etapas iniciais da Educação Básica, cujas tensões se fazem notar ainda nos dias atuais.

Já em 2005, o governo do Estado do Rio de Janeiro intentou induzir a municipalização da Educação Infantil e das sereis iniciais do Ensino Fundamental (até a quarta série ou equivalente) por intermédio da Lei Estadual no 4.528/2005 (RIO DE JANEIRO, 2005) que, entre outros aspectos, determinava que, de um lado, no prazo de três anos cessaria a oferta daquela primeira etapa da Educação Básica (art. 61) e, de outro, no prazo de dez anos seria suspensa a oferta dos anos iniciais de sua segunda etapa (art. 62). Em relação à Educação Infantil, cerca de três anos e meio após a promulgação daquela lei, nova redação veio a ser proporcionada ao art. 61 , agora pelo art. $1^{\circ}$ da Lei
Estadual no 5.311, de 14 de novembro de 2008 (RIO DE JANEIRO, 2008), que reitera o seu cessar, sendo que agora fixado para o ano de 2010, além de planejado pelo Promurj - Resolução SEE no 1.411/1987 (RIO DE JANEIRO.SEE, 1987). Já no que remete aos anos iniciais do Ensino Fundamental o art. 62 veio a ser declarado inconstitucional por meio da Representação de Inconstitucionalidade no 49/2007 (cf. RIO DE JANEIRO, 2005).

Um exemplo dos impactos da Lei Estadual $\mathrm{n}^{\mathrm{o}}$ 4.528/2005 (RIO DE JANEIRO, 2005) na oferta da Educação Infantil e do Ensino Fundamental no Estado do Rio de Janeiro pode ser observado, respectivamente, na série histórica de matrículas indicada nas Tabelas 1 e 2, baseada justamente no período compreendido entre o ano que antecedeu a Lei Estadual no 4.528/2005 e aquele em que a Lei Estadual no 5.311/2008 foi promulgada.

A Tabela 1 permite verificar que o decréscimo total das matrículas estaduais da Educação Infantil é absurdamente acentuado, implicando crescimento negativo de $834 \%$ (-18.505 matrículas, ou seja, de 22.188 para 3.683), especialmente devido à redução, igualmente volumosa, de $851 \%$ da oferta de matrículas na Pré-escola (-18.341 matrículas, ou seja, de 21.547 para 3.206). Dentre essas redes, a única que apresenta algum crescimento foi a municipal, da ordem de 12\% (30.393 matrículas, ou seja, de 253.256 para 283.649) - um pouco mais elevada no âmbito das Creches, 57,4\% (26.480 matrículas, ou

Tabela 1 - Série histórica das matrículas na Educação Infantil (creche e pré-escola) no Estado do Rio de Janeiro, segundo a dependência administrativa e o segmento - 2004-2008

\begin{tabular}{cccccccccccccc}
\hline \multirow{2}{*}{ Anos } & \multicolumn{3}{c}{ Federal } & \multicolumn{4}{c}{ Estadual } & \multicolumn{3}{c}{ Municipal } & \multicolumn{3}{c}{ Privada } \\
\cline { 2 - 13 } & CR & PR & Total & CR & PR & Total & CR & PR & Total & CR & PR & Total \\
\hline 2004 & 131 & 150 & 281 & 641 & 21.547 & 22.188 & 46.067 & 207.189 & 253.256 & 53.026 & 167.111 & 220.137 \\
2005 & 117 & 228 & 345 & 538 & 16.265 & 16.803 & 52.294 & 219.248 & 271.542 & 53.298 & 168.888 & 222.186 \\
2006 & 130 & 144 & 274 & 331 & 13.165 & 13.496 & 55.933 & 214.969 & 270.902 & 52.662 & 148.559 & 201.221 \\
2007 & 175 & 104 & 274 & 503 & 10.710 & 11.213 & 67.374 & 209.116 & 276.490 & 50.627 & 95.000 & 145.627 \\
2008 & 145 & 114 & 259 & 477 & 3.206 & 3.683 & 72.547 & 211.102 & 283.649 & 61.552 & 119.108 & 180.660 \\
\hline
\end{tabular}

Fonte: Rio de Janeiro (2009a), com dados trabalhados por estes autores.

CR: Creche; PR: Pré-escola.

Tabela 2 - Série histórica das matrículas no Ensino Fundamental no Estado do Rio de Janeiro, segundo a dependência administrativa e o segmento - 2004-2008

\begin{tabular}{|c|c|c|c|c|c|c|c|c|c|c|c|c|}
\hline \multirow{2}{*}{ Anos } & \multicolumn{3}{|c|}{ Federal } & \multicolumn{3}{|c|}{ Estadual } & \multicolumn{3}{|c|}{ Municipal } & \multicolumn{3}{|c|}{ Privada } \\
\hline & AI & $\mathbf{A F}$ & Total & AI & AF & Total & AI & AF & Total & AI & AF & Total \\
\hline 2004 & 3.417 & 6.475 & 9.892 & 195.775 & 380.308 & 576.083 & 945.310 & 470.500 & 1.415 .810 & 263.764 & 208.601 & 472.365 \\
\hline 2005 & 3.399 & 6.407 & 9.806 & 167.972 & 374.408 & 542.380 & 970.644 & 480.329 & 1.450 .973 & 267.173 & 208.773 & 475.946 \\
\hline 2006 & 3.788 & 6.485 & 10.273 & 154.978 & 360.683 & 515.661 & 964.040 & 484.144 & 1.448 .184 & 257.556 & 194.317 & 451.873 \\
\hline 2007 & 3.899 & 6.614 & 10.513 & 138.787 & 346.100 & 484.887 & 942.372 & 484.083 & 1.426 .455 & 225.701 & 160.158 & 385.859 \\
\hline 2008 & 3.996 & 6.742 & 10.738 & 114.677 & 348.009 & 462.686 & 917.225 & 495.983 & 1.413 .208 & 291.348 & 209.734 & 501.082 \\
\hline
\end{tabular}

Fonte: Rio de Janeiro (2009a).

AI: Anos iniciais do Ensino Fundamental; AF: Anos finais do Ensino Fundamental. 
seja, de 46.067 para 72.547) do que na Pré-escola que, praticamente, apresenta sinais de certa estagnação no período, 1,9\% (3.913 matrículas, ou seja, de 207.189 para 211.102). Tal desestadualização, ao lado da redução de matrículas igualmente notada na esfera federal e da rede privada, veio acompanhada no período de uma visível municipalização desta etapa inicial da Educação Básica.

Já no caso do Ensino Fundamental, o total de matrículas estaduais passou, entre 2004 e 2008, por um decréscimo da ordem de 19,6\% (-113.397 matrículas, ou seja, de 576.083 para 462.686), diminuição observada em ambos os segmentos: nos anos iniciais, de 41,4\% (-81.098 matrículas, ou seja, de 195.775 para 114.677$)$, enquanto nos anos finais, de 8,5\% (-32.299 matrículas, ou seja, de 380.308 para 348.009). Tal fenômeno é interpretado no diagnóstico que consta no anexo ao PEE do Rio de Janeiro como "tentativa de adequação da rede estadual ao art. 62 da Lei no 4.528/2005, sendo que, no entanto, as redes municipais não aumentaram sua oferta nos anos iniciais do Ensino Fundamental" (RIO DE JANEIRO, 2009), ao contrário, reduzindo-a em 3,0\% (-28.085 matrículas, ou seja, de 945.310 para 917.225).

Contudo, mesmo após a cessão dos efeitos do art. 62 da Lei Estadual no 4.528/2005 (RIO DE JANEIRO, 2005), continuou-se a observar a tendência à retração da oferta da Educação Básica pública no Estado do Rio de Janeiro, acompanhada, a um só tempo, do crescimento da rede privada. Considerando-se o estudo de Davies (2012), constata-se que no período 2006-2011, agora contabilizadas as matrículas totais relativas à Educação Básica no Estado do Rio de Janeiro, ocorreu crescimento negativo da rede estadual deste nível de educação, da ordem de 27,4\% (de 1.490.137 matrículas em 2006, para 1.081.119 em 2011, com evolução de -409.018), acompanhada de uma redução, embora inferior, das matrículas referentes às redes municipais, calculada em $6,5 \%$ (-119.720 matrículas), mas que, em seu conjunto, contrasta com o expressivo crescimento positivo das redes privadas de ensino, da ordem de 17,2\% (147.373 matrículas), no mesmo período.

Tal cenário, além de traduzir o crescente processo de privatização da Educação Básica neste Estado revela que, embora a rede privada tenha crescido, ainda assim não veio a absorver o decremento observado nessas duas redes públicas, o que significa afirmar a existência de um crescente déficit da oferta de Educação Básica no Estado como um todo, curiosamente, conforme salientado por Davies (2012), mesmo em face dos efeitos presumidos da redistribuição de recursos do Fundo de Manutenção e Desenvolvimento da Educação Básica e de Valorização dos Profissionais da Educação (Fundeb) - Lei no 11.494, de 20 de junho de 2007 (BRASIL, 2007b).

\section{O Plano de Desenvolvimento da EDUCAÇÃo (PDE)}

Conforme anteriormente mencionado, o Decreto $\mathrm{n}^{\mathrm{o}}$ 6.094/2007 (BRASIL, 2007a) veio a instituir o PDE, cuja estruturação se deu a partir de seis princípios fundamentais: a visão sistêmica da educação, a territorialidade, o desenvolvimento, o regime de colaboração, a responsabilização (accountability) e a mobilização social o que, sinteticamente, significa afirmar que "busca, de uma perspectiva sistêmica, dar consequência, em regime de colaboração, às normas gerais da educação na articulação com o desenvolvimento socioeconômico que se realiza no território, ordenado segundo a lógica do arranjo educativo local, regional ou nacional" (BRASIL.MEC, 2007, p. 17).

Quando confrontado ao PNE 2001-2010 - Lei $\mathrm{n}^{\mathrm{O}}$ 10.172, de 09 de janeiro de 2001 (BRASIL, 2001) -, o PDE é tratado pelo governo federal não enquanto sua "tradução instrumental" (BRASIL.MEC, 2007, p. 10), mas como superação de certas limitações daquele plano decenal, primordialmente em termos da lacuna deixada em torno da melhoria da qualidade da educação no país, em que pese reconhecer que ele chegou a expor um "bom diagnóstico dos problemas educacionais" (id.).

Entretanto, é importante considerar que o PDE veio a ser promovido em meio à vigência do PNE 2001-2010, o que fez, de certo modo, que viesse a se sobrepor a este último, tornando-o, arbitrariamente, secundário (SOUSA, 2009). Além disto, não se observou articulação entre o PDE e este PNE, já que o primeiro plano é caracterizável por sua centralidade e verticalidade, ou seja, as ações nele previstas foram elaboradas no âmbito do executivo, expressão de uma espécie de recentralização da gestão dos sistemas de ensino no Brasil por intermédio de sua reestruturação na esfera federal (WERLE, 2009). ${ }^{1}$ Cabe ainda observar que um dos problemas relativos à implementação do PNE 2001-2010 (BRASIL, 2001), identificados pelo levantamento do Conselho Nacional de Educação (CNE) sobre algumas das suas avaliações institucionais, refere-se, justamente, à "Articulação tardia do PDE e do PAR com os princípios e metas do PNE" (BRASIL.CNE, 2009, p. 6). No âmbito do Plano Estadual de Educação (PEE) do Rio de Janeiro, tal desarticulação pode documentalmente ser constatada pela inexistência de qualquer referência ao PDE, ou mesmo a um dos seus pilares, como o PAR, neste plano (RIO DE JANEIRO, 2009).

Com isto, a partir do lançamento do PDE, em 2007, as transferências voluntárias de recursos e a assessoria técnica da União, pela via do MEC, junto aos Estados, ao Distrito Federal e, especialmente, em relação aos $\mathrm{Mu}$ nicípios, passaram a estar vinculadas à adesão por parte desses entes federados às metas daquele plano, de modo a 
garantir a sua exequibilidade (ADRIÃO; GARCIA, 2008), contudo, não implicando, necessariamente, ampliação dos recursos destinados à educação (CAMARGO; PINTO; GUIMARÃES, 2008), uma vez que, "no geral transparece um realinhamento das linhas de financiamento do FNDE [Fundo de Desenvolvimento da Educação], pondo fim à dispersão de recursos via pequenos projetos [...] de apoio aos Municípios e estados" (ARAÚJO, 2007, p. 27).

Dentre o conjunto de ações previstas para a consecução do PDE, que inicialmente contou com cerca de 27 programas/diretrizes para, logo em seguida, por sedimentação proporcionada pelo próprio MEC, vir a compreender quase 50, o governo federal elaborou dois planos imbricados: de um lado, o Plano de Metas Compromisso Todos pela Educação e, de outro, o PAR, igualmente consubstanciados no âmbito do Decreto n⿳⺈ 6.094/2007 (BRASIL, 2007a), conforme a seguir discutido.

\section{O Plano de Metas Compromisso Todos Pela Educação}

Conforme indicado acima, o Plano de Metas Compromisso Todos pela Educação, cognominado "Compromisso", consta do Decreto no 6.094/2007 (BRASIL, 2007a), em especial do seu Capítulo I, sendo constituído, originariamente, por 28 diretrizes proclamadas como comprometidas com a "melhoria da qualidade da educação básica" (art. 1ํำ, configurando-se em um dos vetores operacionais do PDE. Para a sua efetivação, este plano sugere estar calçado em ações descentralizadas, de um lado, pela União em relação aos Estados, Municípios e Distrito Federal, isto por intermédio da prática do regime de colaboração, e, de outro, pelo conjunto de entes federados em relação à sociedade civil, nomeadamente por parte "das famílias e da comunidade" (BRASIL, 2007a, art. $1^{\circ}$ ).

No Capítulo II (BRASIL, 2007a) é possível identificar que a dita qualidade da educação básica será orientada para a busca de resultados e com foco na aprendizagem dos alunos, tomando por base as avaliações de larga escala vinculadas ao Índice de Desenvolvimento da Educação Básica (Ideb), indicador, criado, também em 2007, pelo Instituto Nacional de Estudos e de Pesquisas Educacionais Anísio Teixeira (Inep/MEC), qualificado como "objetivo para a verificação do cumprimento de metas fixadas no termo de adesão ao Compromisso". Grosso modo, o Ideb é calculado a partir da taxa de rendimento escolar e do desempenho discente no âmbito do Sistema Nacional de Avaliação da Educação Básica (Saeb), este consistindo em dois processos avaliativos: na Avaliação Nacional da Educação Básica (Aneb) ${ }^{2}$ e na Avaliação Nacional do Rendimento Escolar (Anresc), esta última também cognominada Prova Brasil. ${ }^{3}$ Em outras palavras, quanto maior vier a ser a nota da instituição escolar no teste e, ainda, quanto menor forem as repetências e a evasão escolar registradas, mais alta será a classificação.

Já o Capítulo III do Decreto n⿳0 6.094/2007 (BRASIL, 2007a) remete ao modo de operacionalização do Compromisso junto aos entes federados, cuja adesão é categorizada "voluntária" (arts. 4ำ e 5o), implicando subordinação às metas de qualidade da educação básica do MEC a serem definidas para a evolução do Ideb para cada Estado e Município, além do Distrito Federal, que aderiram ao plano.

No Capítulo IV, último do Decreto nº 6.094/2007 (BRASIL, 2007a), Seção I, já se pode notar que a adesão ao Compromisso condicionará eventuais apoios suplementares e voluntários da União junto às redes públicas de educação básica dos entes federados, nos termos da prestação de assistência técnica ou financeira orientada para os eixos da gestão educacional, da formação de professores e profissionais de serviços e apoio escolar, dos recursos pedagógicos e da infraestrutura física $\left(\S 3^{\circ}\right)$. Assim, para a concretização de tais apoios por parte da União o decreto em questão (BRASIL, 2007a, Capítulo $\mathrm{IV}, \S 5^{\circ}$ ) prevê a celebração de um PAR, em seguida abordado.

\section{O Plano de Ações Articuladas (PAR)}

Conforme destacado na seção anterior, o PAR consiste na base para o termo de convênio entre a União e o ente apoiado pelas ações federais de assistência técnica e financeira aos sistemas locais de ensino, diferenciando-se de um PME na medida em que depende da elaboração de um diagnóstico local pautado em premissas e instrumentos de campo, neste caso, definidos pelo MEC, e não pelas municipalidades.

De acordo com a própria redação do Decreto $\mathrm{n}^{\mathrm{o}}$ 6.094/2007 (BRASIL, 2007a), o PAR consiste em um "conjunto articulado de ações, apoiado técnica ou financeiramente pelo Ministério da Educação, que visa o cumprimento das metas do Compromisso e a observância das suas diretrizes". Com isto, o PAR é apresentado pelo governo federal como proposta de inovação do regime de colaboração no país, isto por intermédio da operacionalização de uma cooperação sistematizada entre União e Municípios.

Do ponto de vista operacional, cada Município deve analisar a sua realidade e, em caso de diagnósticos que apontem situações de fragilidade educacional local, traçar ações propositivas, motivo pelo qual o PAR apresenta três movimentos para a construção de uma política educativa, supostamente, em novas bases: i) seu ponto de partida é um diagnóstico da situação educacional da rede municipal, de caráter participativo, envolvendo desde o dirigente municipal de educação até representantes dos conselhos 
escolares; ii) a partir deste diagnóstico, que objetiva propiciar dados minuciosos da realidade local, devem ser construídas metas e ações para sanar as fragilidades e lacunas detectadas no diagnóstico; por fim, iii) quando o PAR identificar uma situação considerada insuficiente ou crítica, o MEC pode vir a prestar assistência técnica e/ou financeira, isto se as ações prevista pelo município vierem a ser julgadas pertinentes.

Assim, o elemento central para a constituição do PAR é o diagnóstico. Este se divide em quatro grandes setores, chamados pelo MEC de dimensões, a saber: (i) gestão educacional; (ii) formação de professores e dos profissionais de ensino; (iii) infraestrutura e recursos pedagógicos e (iv) práticas pedagógicas e avaliação. Cada uma destas dimensões divide-se em diferentes áreas a serem avaliadas a partir de 52 indicadores. De acordo com os critérios definidos aprioristicamente pelo MEC, cada indicador recebe uma pontuação que se divide em quatro níveis: $1,2,3$ ou 4 . O conceito 1 aponta que o indicador avaliado encontra-se em uma situação crítica, de valência negativa, isento, portanto, de aspectos positivos, sendo necessárias ações de intervenção imediatas. $\mathrm{O}$ conceito 2 descreve uma situação insuficiente, com aspectos negativos superiores aos positivos, impondo também ações imediatas. Já o conceito 3 descreve uma realidade oposta às descritas anteriormente, pois denota uma situação dita satisfatória, em que prevalecem aspectos positivos em relação aos negativos, mas que implicam ações parciais de modo a favorecerem o desempenho do indicador analisado. Por fim, a pontuação 4 descreve uma situação positiva, não existindo, em tese, aspectos negativos em relação ao indicador avaliado e, portanto, não havendo necessidade do planejamento de ações (BRASIL.MEC, 2008).

Quando o indicador não corresponde à realidade local, não deve ser pontuado. Ou seja, no PAR deve constar, para este indicador, "não avaliado" (n/a). Vale ressaltar que o MEC pode prestar assistência técnica e/ou financeira, exclusivamente, para os indicadores que se encontram em situação crítica (1) ou insuficiente (2). Porém, para esses indicadores, o Município deve, necessariamente, incluir em seu PAR ações que apontem possibilidade de superação dos aspectos negativos encontrados no indicador em questão.

Segundo o MEC, todos os Municípios do país aderiram ao Plano de Metas, o que pode ser aferido através do termo de adesão disponível no site deste Ministério, em que constam as assinaturas do dirigente municipal e do Ministro da Educação, o que pressupõe que todas essas localidades deveriam ter elaborado o seu respectivo PAR. Todavia, é possível constatar que há localidades que, até dezembro de 2012, ainda não o apresentaram, como o Município de São Paulo, ou mesmo Brasília. Vale também ressaltar que, até o mês de dezembro de 2013, não se constata no site do $\mathrm{Simec}^{4}$ o PAR dos Estados, isto é, estão disponibilizados somente o dos Municípios.

\section{BALANÇO DO PAR NOS MUNICÍPIOS FLUMINENSES}

Dos 92 Municípios do Estado do Rio de Janeiro, verifica-se, até o mês de janeiro de 2013, que 90 (98\%) possuem os seus respectivos PARs disponíveis no site do Simec (do qual se extraíram todos os dados aqui analisados), com exceção de Cambuci e de Nova Iguaçu. ${ }^{5}$

Ainda com base no site do Simec, foi consultada a parte intitulada "síntese da dimensão" do PAR dos 90 Municípios do Rio de Janeiro, que sintetiza numericamente as pontuações atribuídas aos 52 indicadores que perpassam as quatro dimensões do PAR. Para análise desses dados, as pontuações 4 e 3 foram consideradas como avaliações positivas, enquanto as pontuações 1 e 2 como negativas, sendo excluídos do cômputo os indicadores não avaliados (n/a). A partir destas avaliações expressas em cada PAR, os Municípios foram divididos em cinco grupos: Muito Frágil (MF), Frágil (F), Médio (M), Bom (B) e Muito Bom (MB). Para este cálculo, foi considerado o número total $(\mathrm{N})$ de indicadores que obtiveram boas pontuações, (positiva / 4 ou satisfatória / 3) atribuídas pelos Municípios no universo total $(\mathrm{T})$ dos indicadores, excetuando os não avaliados (n/a). Desta forma, o Município classificado como Muito Bom (MB) foi aquele que atribuiu pontuação 3 (satisfatória) ou 4 (positiva) a mais de $80 \%$ dos seus indicadores, enquanto o Município classificado como Muito Frágil (MF) aquele que somente atribuiu até 20\% de pontuação Boa (B), isto é, 3 e 4 aos seus indicadores. O mesmo raciocínio foi feito para os demais grupos, sendo atribuído um intervalo de $20 \%$ para cada um. Assim, a classificação dos Municípios foi feita da seguinte forma: (MF) $0 \leq \mathrm{N} \leq 0,2 \mathrm{~T}$; (F) $0,2 \mathrm{~T}<\mathrm{N} \leq 0,4 \mathrm{~T}$; (M) $0,4 \mathrm{~T}<\mathrm{N} \leq 0,6 \mathrm{~T}$; B $0,6 \mathrm{~T}<\mathrm{N} \leq 0,8 \mathrm{~T}$ e $(\mathrm{MB}) 0,8 \mathrm{~T}<\mathrm{N} \leq \mathrm{T}$.

Os números do Gráfico 1 sugerem que os Municípios do Estado possuem um quadro educacional relativamente satisfatório, o que levanta dúvida quanto a possibilidade de estarem refletindo, de fato, a realidade educacional do Estado, especialmente se considerado, por exemplo, os últimos resultados do Ideb, divulgados pelo Inep/ MEC em 2011, no qual se constata sua classificação na quinta pior posição do país. ${ }^{6}$ Dentre as 90 localidades analisadas, salta aos olhos a predominância dos grupos MB (19\%) e B (34\%), totalizando 53\%, seguido dos grupos médio e frágil com, respectivamente, $30 \%$ e $15 \%$. Em contrapartida, apenas $2 \%$ dos Municípios do Rio de Janeiro foram parcimoniosos na distribuição de pontuações favoráveis aos indicadores que integram o PAR. 
Gráfico 1 - Segmentação dos Municípios a partir do PAR 2007-2010

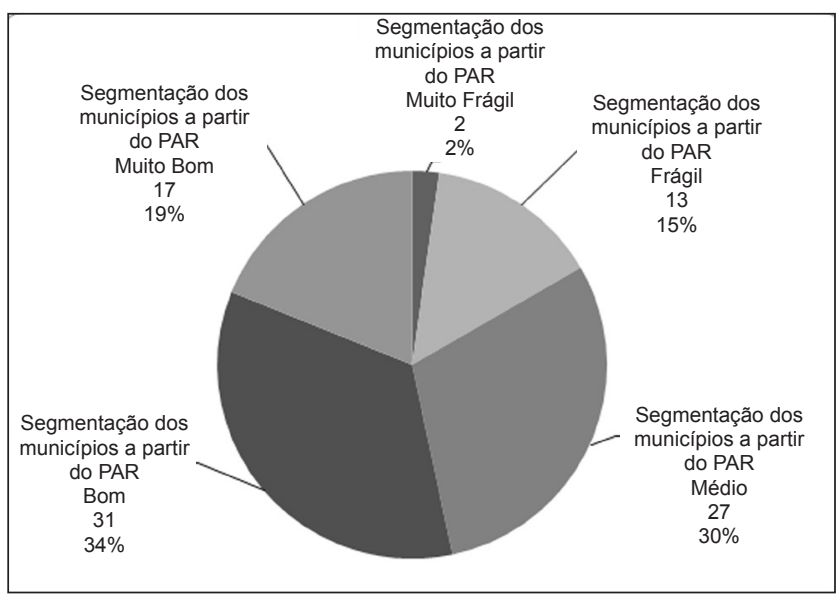

Fonte: SIMEC. ${ }^{7}$

Nota: Dados trabalhados pelos autores.

É importante considerar que os critérios presentes nas pontuações que devem ser atribuídas aos indicadores do PAR, conforme anteriormente visto, consistem em padrões a priori definidos pelo MEC, que servem para apreciação de um dado indicador (BRASIL.MEC, 2008). As pontuações 1 e 4 descrevem situações antagônicas, porém utilizam critérios menos imprecisos em relação às demais. É recorrente o uso de palavras vagas nos padrões descritos pelo MEC, em especial, no conceito 3, como "parte", "parcialmente", "eventualmente" ou expressões que denotam processos inconclusos, como "políticas em fase de implementação", neste último caso revelando muito pouco sobre a realidade educacional local, pois não define prazos e este processo pode se estender de modo indefinido, mormente quando não houver vontade política por parte dos poderes instituídos, nem mobilização suficiente para assegurar, por exemplo, a implementação de "planos de carreira", um dos indicadores da gestão educacional. Neste sentido, a pontuação 3 é bastante problemática, até porque foi a segunda pontuação mais usada pelos Municípios deste Estado, observável em 29 localidades (32\%), perdendo apenas para a pontuação 4 , que teve a preferência de 34 Municípios (38\%). Em alguns casos, o padrão dado pelo MEC soa como algo incoerente e impróprio, tendo em vista que o conceito 3 pressupõe uma situação satisfatória, com mais aspectos positivos do que negativos. O padrão descrito em vários indicadores para o nível 3 sugere uma situação insuficiente ou mesmo crítica. A título de exemplificação, vale citar alguns critérios definidos como nível 3 presentes nas quatro dimensões.

A dimensão "gestão educacional" se divide em cinco áreas, sendo que uma destas é a "gestão democrática". A "existência, composição e atuação do Conselho Municipal de Educação (CME)" é um dos indicadores que avalia a gestão democrática. Em relação a este indicador, o Município deve apontar conceito 3:

quando existe um CME implementado, com regimento interno, escolha democrática dos conselheiros, porém nem todos os segmentos estão representados; o CME zela pelo cumprimento das normas; não auxilia a SME no planejamento municipal de educação, na distribuição de recursos, no acompanhamento e avaliação das ações educacionais, apenas valida o plano da SME (BRASIL.MEC, 2008, p. 14).

Como considerar como situação satisfatória um CME cuja atuação se restringe a validar o plano da SME e tampouco possui todos os seus segmentos previstos representados? Parece que tal CME apenas legitima a política do executivo local, pouco contribuindo para uma gestão efetivamente democrática.

O "desenvolvimento educação básica", outra área da dimensão "gestão educacional", possui como um dos indicadores a "divulgação e análise dos resultados das avaliações oficiais do MEC" (ibid., p. 19). Este recebe a pontuação 3:

quando a SME e as escolas divulgam, em parte, os resultados das avaliações oficiais do MEC; apenas parte destes resultados é analisada e discutida com comunidade escolar (o CE [Conselho Escolar] raramente participa desta discussão); gerando eventualmente estratégias para melhoria. Divulgação e análise dos resultados das avaliações do MEC [grifo nosso] (ibid., p. 19).

Tendo em vista o uso de palavras pouco precisas, nada indica que a divulgação "em parte" dos resultados e a análise de "apenas parte" será significativa, podendo contribuir para rever as práticas pedagógicas, o que seria satisfatório. Uma situação ainda mais perplexa ocorre com o indicador "relação com a comunidade/promoção de atividades e utilização da escola como espaço comunitário", da área "comunicação com a sociedade", também integrante da dimensão gestão educacional. Afinal o conceito 3 deve ser dado:

quando as escolas, raramente são utilizadas pela comunidade em atividades esportivas, culturais e/ou para discussão de questões de interesse da comunidade; a comunidade não é estimulada a participar e ocupar o espaço escolar para desenvolver atividades de integração; a SME esporadicamente apóia [sic.] ou estimula esta forma de integração [grifo nosso] (ibid., p. 21).

O padrão acima descrito não se coaduna com o adjetivo satisfatório, pois revela um distanciamento 
entre escola e comunidade. Todavia, muitos Municípios devem ter assinalado 3 porque os critérios definidos correspondem à realidade local, mas tal padrão não deveria ser chamado de satisfatório, sobretudo, quando o indicador foca a relação escola-comunidade.

A dimensão "formação de professores" também se divide em cinco áreas. A "existência e implementação de políticas de formação continuada de professores que atuam na Educação Infantil" é um dos indicadores da área "formação de professores". A este indicador é atribuído conceito 3 "quando existem políticas em fase de implementação, voltadas para a formação continuada dos professores que atuam na Educação Infantil" (ibid., p. 26). Tal situação pode descrever a realidade de muitos Municípios, mas qualificar de satisfatória uma política em "fase de implementação" é, no mínimo, temerário, pois, há muito, percebe-se que é recorrente um fosso entre o anunciado e o efetivamente realizado no âmbito das políticas públicas.

"Avaliação da aprendizagem dos alunos" é uma das duas áreas que compõem a dimensão "práticas pedagógicas e avaliação", sendo que a "utilização do tempo para assistência individual/coletiva aos alunos que apresentam dificuldade de aprendizagem" corresponde a um dos seus indicadores. No PAR, deve constar o conceito 3 "quando o tempo para assistência individual e/ou coletiva não é informado como um direito que o aluno terá, durante todo o ano letivo, e acontece somente após o término do bimestre/período de avaliação final [grifo nosso]" (ibid., p. 33). Como considerar satisfatória uma situação em que o aluno sequer conhece o seu direito? Além disso, terá assistência apenas em momentos pontuais. Ainda que a Ldben $n^{0}$ 9.394/1996 (BRASIL, 1996) permita esse tipo de assistência, a mesma lei sinaliza que a recuperação deve ocorrer, preferencialmente, ao longo do período letivo, o que, do ponto de vista pedagógico, implica uma assistência mais sólida e, portanto, com maiores chances de êxito.

"Instalações físicas gerais" é uma das três áreas que integram a dimensão "infraestrutura e recursos pedagógicos". Um de seus indicadores de análise é a "existência e funcionalidade de laboratórios (Informática e de Ciências)" (BRASIL.MEC, 2008, p. 35). Deve-se atribuir conceito 3 a este indicador "quando existem laboratórios de ciências, informática e/ou artes, porém pouco equipados e em quantidades insuficientes para atender as necessidades dos professores e alunos. Raramente alunos e professores utilizam os laboratórios de informática e ciências" (id.). Vale reconhecer que os padrões descritos nos indicadores que perpassam a dimensão "infraestrutura" são, em geral, menos vagos que os demais, embora trazendo à vista as dificuldades de se conceituá-lo "satisfatórios".
Ou seja, os padrões descritos para a pontuação 3 dos indicadores do PAR podem ter contribuído para inflacionar um caráter supostamente promissor da realidade educacional dos Municípios do Rio de Janeiro. O Gráfico 1, indicado anteriormente, apresenta números otimistas, mas ao se analisar os critérios que qualificam cada nível de pontuação é possível perceber incongruências entre a qualificação atribuída (satisfatória) e a situação dada. Ademais, cabe lembrar que o conceito 3 implica o reconhecimento formal de que o indicador possui mais aspectos positivos do que negativos, podendo até haver ajustes, mas não requer ações no PAR. Isto pode gerar um certo imobilismo por parte das autoridades municipais, pois o indicador encontra-se, em tese, de forma satisfatória. Em contrapartida, tal quadro permite ao MEC não só ser parcimonioso em sua assistência financeira aos Municípios, como pode também exibir números mais confortáveis nas estatísticas oficiais, ainda que distantes da concretude da realidade.

A imprecisão contida em vários indicadores se mostra de forma mais intensa na dimensão "gestão educacional". Nas dimensões "infraestrutura" e "formação de professores" o caráter subjetivo torna-se mais contido pela própria natureza dos seus indicadores. A existência de uma quadra de esportes ou de um laboratório é algo mais fácil de ser determinada, como também a qualificação acadêmica de um dado profissional. Portanto, a natureza diferenciada dos padrões que sustentam as dimensões do PAR pode contribuir para a compreensão dos dados obtidos no Gráfico 2.

Gráfico 2 - Fragilidades apontadas no PAR - 2007-2010

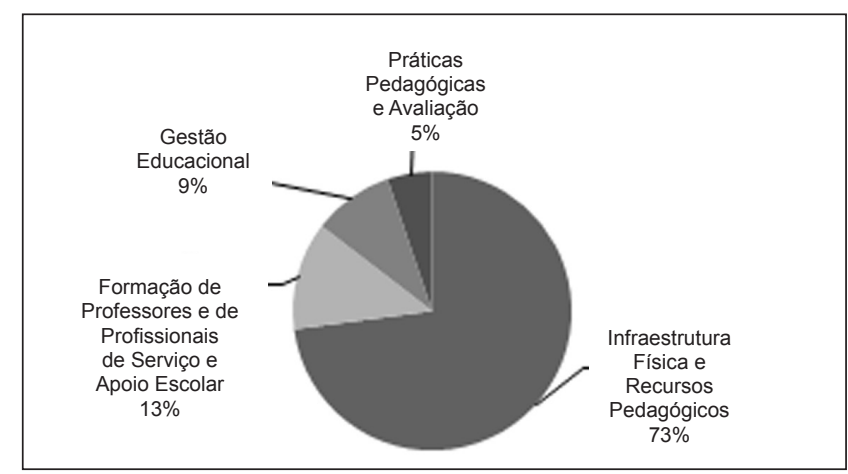

Fonte: SIMEC. 8

Nota: Dados trabalhados pelos autores.

No PAR, a dimensão "infraestrutura física e recursos pedagógicos" foi apontada por $73 \%$ dos Municípios do Estado Rio de Janeiro como o setor mais frágil, seguido pela "formação de professores e dos profissionais de serviço e apoio escolar" com 13\%. Contudo, pelos motivos expostos, não se deve concluir que as demais dimensões 
(gestão e práticas) estejam organizadas efetivamente de forma satisfatória, como sugere as pontuações atribuídas aos respectivos indicadores que alicerçam o diagnóstico presente no PAR. Se vários padrões apresentam incongruências, cabe ressaltar que 68 (76\%) dos 90 Municípios que apresentaram o PAR recorreram ao "não avaliado" para alguns de seus indicadores. No conjunto desses 68 Municípios, 63 (93\%) apontaram indicadores que integram a dimensão "gestão educacional".

\section{CONSIDERAÇÕES FINAIS}

Conforme visto, a partir de 2005, passou-se a registrar uma diminuição crescente da oferta estadual das etapas iniciais da Educação Básica, vindo a culminar, em 2008, na municipalização quase integral do atendimento da Educação Infantil, ao lado da estagnação das matrículas municipais referentes às séries iniciais do Ensino Fundamental, com aumento da oferta da rede privada. Tal quadro viria a evoluir, em 2011, para uma redução das matrículas da Educação Básica pública como um todo, concomitantemente a uma maior participação da rede particular, embora não expondo taxas que indiquem absorção dos déficits gerados pela retração da rede pública. Neste contexto, as políticas ditas descentralizadoras consubstanciaram-se, na prática, em processos quer de desconcentração da administração educacional estadual, tipicamente à margem da partilha de poderes e da observância do regime de colaboração, quer de privatização da Educação Básica, caracteristicamente marcada, de um lado, por movimentos de cessão ou retração da oferta pública de algumas de suas etapas, e de outro, pela formação de nichos de demanda educacional reprimida a serem atendidos, justamente, pela rede particular de ensino.

Em que pese o fato de, segundo dados oficias, a adesão ao PAR ter sido registrada em escala nacional, parece plausível presumir que, em meio ao cenário acima retraçado, sua disseminação no Estado do Rio de Janeiro tenha particularmente sido impulsionada pelos desafios postos aos Municípios fluminenses de, a partir de 2005, virem a responsabilizarem-se integralmente pela cobertura da Educação Infantil e dos anos iniciais do Ensino Fundamental. Com isto, os diagnósticos do PAR elaborados localmente, em especial os que resultam em avaliações conceituadas insatisfatórias, nas quais prevalecem aspectos negativos em relação aos positivos, podem não estar exprimindo, de fato, as realidades locais, e sim o traçar de um perfil que eventualmente favoreça a concessão de determinadas transferências de recursos por parte da União, acompanhada de assistência técnica, de modo a subsidiar um provável aumento da oferta local da educação municipal.
Um segundo problema identificado remete ao fato de que, apesar de pouco mais da metade desses diagnósticos apontar contextos educacionais prósperos, o próprio índice oficial que se presta à verificação do cumprimento de metas fixadas no termo de adesão do Município ao Compromisso/PDE, o Ideb, classificava o Estado do Rio de Janeiro, em 2011, na quinta pior posição do País, conforme já assinalado. Tal contradição pode decorrer, quer das inconsistências e incoerências internas relativas aos indicadores e critérios empregados pelo PAR, analisadas anteriormente; quer de uma simplificação da diagnose efetuada pelo Município, pois atribuindo pontuações mais elevadas estes se vêem desobrigados da descrição das ações do PAR que deveriam ser adotadas em face da identificação de eventuais fragilidades educacionais locais; quer, agora, do escamotear estratégico dessas próprias fragilidades com vistas a não torná-las públicas, ou mesmo de forma a não implicar maior regulação por parte das políticas do governo feral (já que no caso das avaliações insatisfatórias o Município tem que fazer frente às ações previstas no plano). De qualquer modo, essas duas últimas hipóteses se configuram restritivas em relação a uma eventual assistência técnica por parte do governo federal e, sobretudo, transferência de recursos financeiros que poderiam apoiar a solução dos problemas identificados, mas que foram negados ou escamoteados.

Uma terceira e última questão é que dentre os 52 indicadores que até então serviam ao diagnóstico do PAR, poucos remetem diretamente às condições de aprendizagem, o que implica afirmar, conforme identificado por Souza e Monteiro (2010, p. 20), que nem sempre resultados do Ideb "ou das pontuações atribuídas aos indicadores se prestam a avaliações de mesmo sentido [...]". Em outras palavras, corre-se o risco, por exemplo, de uma determinada rede municipal fluminense vir a concentrar esforços na ambiência pedagógica, justo quando o foco das ações deveria, em função da natureza dos resultados da avaliação do PAR, estar originalmente direcionado ao plano da gestão educacional. Ao revés, poderia negligenciar a possibilidade de elaboração de políticas locais voltadas à superação de determinadas dificuldades de ordem pedagógica no âmbito do Sistema Municipal de Ensino, isto pelo fato desta não estar consubstanciada no conjunto de ações do PAR.

A consideração dos resultados do PAR no Estado do Rio de Janeiro, portanto, exige cautela, pois podem tanto contribuir para o conhecimento e superação de algumas das debilidades da educação fluminense, quanto, no limite dessa possibilidade, induzir os Sistemas Municipais de Ensino a uma espécie de uniformização de suas políticas por meio da regulação federal, à margem das múltiplas realidades educacionais locais, em detrimento, portanto, de demandas de maior autencidade. Nesta perspectiva, 
parece plausível que esses diagnósticos estejam reforçando a tese de Voss (2011, p. 63) em relação à política maior do PDE, pois, ao invés de estarem fornecendo dados sobre as realidades locais, de modo a dotá-las de maior transparência, podem, justo ao contrário, estar tornandoas "mais opacas, pois o que está em jogo são imagens fabricadas para dar visibilidade e legitimidade aos resultados que devem ser alcançados".

Diante do exposto, concluímos pela necessidade de realização de pesquisas mais abrangentes que possam confrontar as informações do PAR em diferentes Estados da federação, permitindo avaliar, em especial, até que ponto alguns dos problemas identificados no Estado do Rio de Janeiro, como as possíveis disfunções locais dos diagnósticos, consistem em um caso particular ou exprimem uma tendência mais ampla relativa à sua difusão em outras regiões. Importante destacar que, apesar das fragilidades notadas nos diagnósticos do PAR fluminense, não se deve perder de vista que a sua configuração é, sobremaneira, dependente da ressignificação que lhe é proporcionada no âmbito das políticas públicas locais, portanto, resultante da mediação dos diversos atores sociais direta e indiretamente envolvidos com a sua formulação, implantação e acompanhamento.

\section{REFERÊNCIAS}

ABREU, Mariza. Organização da educação nacional na constituição e na LDB. 3. ed. Ijuí: Ed. Unijuí, 2002.

ABREU, Mariza; SARI, Marisa Timm. Colaboração entre União, Estados/DF e Municípios na área da educação. Cadernos Aslegis, Brasília, v. 3, n. 8, p. 9-15, maio-ago. 1999.

ADRIÃO, Theresa Maria de Freitas; GARCIA, Teise. Oferta educativa e responsabilização no PDE: o Plano de Ações Articuladas. Cadernos de Pesquisa, São Paulo, v. 38, n. 135, p. 779-796, set.-dez. 2008.

ALCÂNTARA, Alzira Batalha. Pacto federativo, educação e participação: uma República para todos? Niterói, 2011. 356 f. Tese (Doutorado em Educação) - Faculdade de Educação, Universidade Federal Fluminense.2011.

ARAÚJO, Luiz. Os fios condutores do PDE são antigos. Jornal de Políticas Educacionais, Curitiba, v. 1, n. 2, p. 24-31, set. 2007.

ARRETCHE, Martha. Federalismo e relações intergovernamentais no Brasil: a reforma de programas sociais. Dados: Revista de Ciências Sociais, Rio de Janeiro, v. 45, n. 3, p. 431-458, 2002a.

ARRETCHE, Martha. Políticas sociais no Brasil: descentralização em um Estado federativo. Revista Brasileira de Ciências Sociais, Rio de Janeiro, v. 14, n. 40, p.111-141, jun. 1999.

ARRETCHE, Martha. Relações federativas nas políticas sociais. Educação \& Sociedade, Campinas, v. 23, n. 80, p. 25-48, set. $2002 b$.

BRASIL. Conselho Nacional de Educação. Câmara de Educação Básica. Parecer n⿳ำ 30, de 12 de setembro de 2000.
Define sistema de ensino dentro do ordenamento jurídicoadministrativo, tendo-se como referência a organização da educação nacional. Diário Oficial [da] República Federativa do Brasil, Brasília, 6 out. 2000.

BRASIL. Portaria CNE/CP no $\mathbf{1 0}$, de 6 de agosto de 2009 . Indicações para subsidiar a construção do Plano Nacional de Educação 2011-2020. Brasília: CNE/CP, 2009.

BRASIL. Constituição [de 1988] da República Federativa do Brasil. Diário Oficial [da] República Federativa do Brasil, Brasília, 5 out. 1988.

BRASIL. Decreto n. 6.094, de 24 de abril de 2007. Dispõe sobre a implementação do Plano de Metas Compromisso Todos pela Educação, pela União Federal, em regime de colaboração com Municípios, Distrito Federal e Estados, e a participação das famílias e da comunidade, mediante programas e ações de assistência técnica e financeira, visando a mobilização social pela melhoria da qualidade da educação básica. Diário Oficial [da] República Federativa do Brasil, Brasília, 25 de abril de $2007 \mathrm{a}$.

BRASIL. Emenda Constitucional no 59, de 11 de novembro de 2009. Acrescenta $\S 3^{\circ}$ ao art. 76 do Ato das Disposições Constitucionais Transitórias para reduzir, anualmente, a partir do exercício de 2009, o percentual da Desvinculação das Receitas da União incidente sobre os recursos destinados à manutenção e desenvolvimento do ensino de que trata o art. 212 da Constituição Federal, dá nova redação aos incisos I e VII do art. 208, de forma a prever a obrigatoriedade do ensino de quatro a dezessete anos e ampliar a abrangência dos programas suplementares para todas as etapas da educação básica, e dá nova redação ao $\S 4^{\circ}$ do art. 211 e ao $\S 3^{\circ}$ do art. 212 e ao caput do art. 214, com a inserção neste dispositivo de inciso VI. Diário Oficial da União [da] República Federativa do Brasil, Brasília, 12 nov. 2009.

BRASIL. Instituto Brasileiro de Geografia e Estatística. Diretoria de Pesquisas. Coordenação de População e Indicadores Sociais. Perfil dos municípios brasileiros 2011 [Pesquisa de Informações Básicas Municipais]. Rio de Janeiro: IBGE, 2012.

BRASIL. Lei no 12.695, de 25 de julho de 2012. Dispõe sobre o apoio técnico ou financeiro da União no âmbito do Plano de Ações Articuladas; altera a Lei no 11.947, de 16 de junho de 2009, para incluir os polos presenciais do sistema Universidade Aberta do Brasil na assistência financeira do Programa Dinheiro Direto na Escola; altera a Lei no 11.494 , de 20 de junho de 2007, para contemplar com recursos do FUNDEB as instituições comunitárias que atuam na educação do campo; altera a Lei no 10.880 , de 9 de junho de 2004, para dispor sobre a assistência financeira da União no âmbito do Programa de Apoio aos Sistemas de Ensino para Atendimento à Educação de Jovens e Adultos; altera a Lei no $\mathbf{8 . 4 0 5}$, de 9 de janeiro de 1992; e dá outras providências. Diário Oficial da União [da] República Federativa do Brasil, Brasília, 26 jul. 2012.

BRASIL. Lei $\mathrm{n}^{\mathrm{o}}$ 10.172, de 09 de janeiro de 2001. Aprova o Plano Nacional de Educação (PNE). Diário Oficial [da] República Federativa do Brasil, Brasília, 10 jan. 2001.

BRASIL. Lei no 11.494 , de 20 de junho de 2007. Regulamenta o Fundo de Manutenção e Desenvolvimento da Educação Básica e de Valorização dos Profissionais da Educação - FUNDEB, de que trata o art. 60 do Ato das Disposições Constitucionais Transitórias; altera a Lei no 10.195 , de 14 de fevereiro de 2001; 
revoga dispositivos das Leis nos 9.424, de 24 de dezembro de 1996, 10.880, de 9 de junho de 2004, e 10.845, de 5 de março de 2004; e dá outras providências. Diário Oficial da União [da] República Federativa do Brasil. Brasília. 21 jun. 2007 b.

BRASIL. Lei no 4.024, de 20 de dezembro de 1961. Fixa as diretrizes e bases da educação nacional. Diário Oficial [da] República Federativa do Brasil, Brasília, 27 dez. 1961.

BRASIL. Lei no 5.692 , de 11 de agosto de 1971. Fixa diretrizes e bases para o ensino de $1^{\mathrm{O}}$ e $2^{\mathrm{O}}$ graus, e dá outras providências. Diário Oficial [da] República Federativa do Brasil, Brasília, 12 ago. 1971.

BRASIL. Lei no 9.394, de 20 de dezembro de 1996. Estabelece as Diretrizes e Bases da Educação Nacional. Diário Oficial [da] República Federativa do Brasil, Brasília, 23 dez. 1996.

BRASIL. Ministério da Educação. O Plano de Desenvolvimento da Educação: razões, princípios e programas. Brasília: MEC, 2007.

BRASIL. Plano de Metas Compromisso Todos pela Educação: instrumento de campo. Brasília, MEC, 2008.

CAMARGO, Rubens Barbosa de; PINTO, José Marcelino de Rezende; GUIMARÃES, José Luiz. Sobre o financiamento no Plano de Desenvolvimento da Educação. Cadernos de Pesquisa, São Paulo, v. 38, n. 135, p. 817-839, set.-dez. 2008.

CASSASUS, Juan. Tarefas da educação. Campinas: Autores Associados, 1995.

CURY, Carlos Roberto Jamil. Impacto sobre as dimensões de acesso e qualidade. In: GRACIANO, Mariângela (Org.). O Plano de Desenvolvimento da Educação. São Paulo: Ação Educativa, 2007, v. 4, p. 14-15.

CURY, Carlos Roberto Jamil. O regime de colaboração no ordenamento jurídico da educação escolar brasileira. In: BRASIL. Ministério da Educação. Secretaria de Educação Básica. Programa Nacional de Capacitação de Conselheiros Municipais de Educação Pró-Conselho: caderno de referência. Brasília: MEC/SEB, 2004, p. 10-23.

CURY, Carlos Roberto Jamil. Por um sistema nacional de educação. São Paulo: Moderna, 2010.

DAVIES, Nicholas. Alguns desafios do financiamento da educação: a responsabilidade pelo ensino na legislação, a capacidade tributária dos governos e o impacto do Fundef e do Fundeb na educação. In: PARENTE, Juliano Mota; PARENTE, Cláudia da Mota Darós (Org.). Política, gestão e financiamento da educação. Aracajú: Ed.UFS, 2012, p. 145-163.

DOURADO, Luiz Fernandes. Sistema nacional de educação, federalismo e os obstáculos ao direito à educação básica. Educação \& Sociedade, Campinas, v. 34, n. 124, p. 761-785, jul.-set. 2013.

FARENZENA, Nalu; LUCE, Maria Beatriz. O Regime de Colaboração intergovernamental. In: GRACIANO, Mariângela (Org.). O Plano de Desenvolvimento da Educação. São Paulo: Ação Educativa, 2007, v. 4, p. 9-13.

MARTINS, Ângela Maria. A descentralização como eixo das reformas do ensino: uma discussão da literatura. Educação \& Sociedade, Campinas, v. 22, n. 77, p. 28-48, dez. 2001.

PONTUAL, Pedro. Possibilidades e limites da participação. In: GRACIANO, Mariângela (Org.). O Plano de Desenvolvimento da Educação. São Paulo: Ação Educativa, 2007, v. 4, p. 49-51.
RAMOS, Elizabete. De que participação estamos falando? In: GRACIANO, Mariângela (Org.). O Plano de Desenvolvimento da Educação. São Paulo: Ação Educativa, 2007, v. 4, p. 56-58.

RIO DE JANEIRO (Estado). Lei no 4.528, de 28 de março de 2005. Estabelece as diretrizes para a organização do sistema de ensino do Estado do Rio de Janeiro. Diário Oficial do Estado do Rio de Janeiro, Rio de Janeiro, 29 de março de 2005.

RIO DE JANEIRO (Estado). Lei no 5.311, de 14 de novembro de 2008. Altera a Lei Estadual no. 4.528, de 28 de março de 2005, e autoriza o Poder Executivo a criar no âmbito da Secretaria de Estado de Educação o "programa escola-infância". Diário Oficial [do] Estado do Rio de Janeiro, Rio de Janeiro, 17 de novembro de 2008.

RIO DE JANEIRO (Estado). Lei no 5.597, de 18 de dezembro de 2009. Institui o Plano Estadual de Educação - PEE-RJ, e dá outras providências. Diário Oficial [do] Estado do Rio de Janeiro, Rio de Janeiro, 19 de dezembro de 2009.

RIO DE JANEIRO. Secretaria Estadual de Educação. Resolução no 1.488 , de 08 de março de 1989. Diário Oficial do Estado, Rio de Janeiro, 12 mar. 1989.

RIO DE JANEIRO. Secretaria Estadual de Educação. Resolução no 1.411, de 03 de dezembro de 1987. Diário Oficial do Estado, Rio de Janeiro, 07 dez. 1987.

SARI, Marisa Timm; MARTINS, Ricardo Chaves de Rezende; CASTIGLIONI, Vera Lúcia Baptista. Organização da educação nacional no contexto do fortalecimento da Educação Básica: o papel do município. In: BRASIL. Ministério da Educação. Secretaria de Educação Básica. Pradime: Programa de Apoio aos Dirigentes Municipais de Educa. Brasília: MEC/SEB, 2006, p. 79-130 (Caderno de Textos, 1).

SAVIANI, Dermeval. Educação brasileira: estrutura e sistema. 7. ed. Campinas: Autores Associados, 1996.

SAVIANI, Dermeval. Sistema nacional de educação articulado ao Plano Nacional de Educação. Revista Brasileira de Educação, Rio de Janeiro, v. 15, n. 44, p. 380-412, maio-ago. 2010.

SAVIANI, Dermeval. Sistemas de ensino e planos de educação: o âmbito dos municípios. Educação \& Sociedade, Campinas, v. 20, n. 69, p. 119-136, dez. 1999.

SOUSA, Bartolomeu José Ribeiro de. O Plano de Ações Articuladas (PAR) como instrumento de planejamento da educação: o que há de novo? In: SIMPÓSIO BRASILEIRO DE POLÍTICA E ADMINISTRAÇÃO DA EDUCAÇÃO, 25. CONGRESSO IBERO-AMERICANO DE POLÍTICAS E ADMINISTRAÇÃO DA EDUCAÇÃO, 2., 2011, São Paulo. Anais. Recife: ANPAE, 2011.

SOUSA, Bartolomeu José Ribeiro de. Os planos e a educação básica no Brasil - O PDE em análise. In: SIMPÓSIO BRASILEIRO DE POLÍTICA E ADMINISTRAÇÃO DA EDUCAÇÃO, 24., 2009, Vitória. Anais. Rio de Janeiro: ANPAE, 2009.

SOUZA, Celina; CARVALHO, Inaiá Maria Moreira de. Reforma do Estado, descentralização e desigualdades. Lua Nova: Revista de Cultura e Política, São Paulo, n. 48, p. 187-212, 1999.

SOUZA, Donaldo Bello de; DUARTE, Marisa Ribeiro Teixeira; OLIVEIRA, Rosimar de Fátima. CMEs no Brasil: uma cartografia a partir dos estudos teórico-empíricos. In: SOUZA, 
Donaldo Bello de (Org.). Mapa dos conselhos municipais de educação no Brasil: criação, implantação e funcionamento institucional e sociopolítico. São Paulo: Edições Loyola, 2013. p. 23-55.

SOUZA, Donaldo Bello de; FARIA, Lia Ciomar Macedo de. O processo de construção da educação municipal pós-LDB 9.394/96: políticas de financiamento e gestão. In: (Org.). Desafios da educação municipal. Rio de Janeiro: DP\&A, 2003. p. 45-84.

SOUZA, Donaldo Bello de; VASCONCELOS, Maria Celi Chaves. CMEs no estado do Rio de Janeiro: sobre a autonomia concedida e a submissão herdada. In: SOUZA, Donaldo Bello de (Org.). Mapa dos conselhos municipais de educação no Brasil: criação, implantação e funcionamento institucional e sociopolítico. São Paulo: Edições Loyola, 2013, p. 129-148.

SOUZA, Donaldo Bello de; VASCONCELOS, Maria Celi Chaves. CMEs no estado do Rio de Janeiro: considerações sobre o funcionamento institucional e sociopolítico a partir de 28 de suas localidades. In: VALLE, Bertha de Borja Reis do; VASCONCELOS, Maria Celi Chaves (Org.). Conselhos municipais de educação: organização e atribuições nos sistemas de ensino do estado do Rio de Janeiro. Rio de Janeiro: Quartet; Faperj, 2012.

SOUZA, Márcia Helena de Moraes; MONTEIRO, Silas Borges. O IDEB e o diagnóstico das redes de ensino dos municípios prioritários no Plano de Ações Articuladas de Mato Grosso. In: ENCONTRO NACIONAL DE DIDÁTICA E PRÁTICA DE ENSINO,15., 2010, Belo Horizonte. Anais. Belo Horizonte: Endipe, 2010. 1 CD-ROM.

VASCONCELOS, Maria Celi Chaves. Conselhos municipais de educação: criação e implantação em face das novas atribuições dos sistemas de ensino. In: SOUZA, Donaldo Bello de; FARIA, Lia Ciomar Macedo de (Org.). Desafios da educação municipal. Rio de Janeiro: DP\&A, 2003. p. 107-122.

VENEZIANO, Alicia. Evolución del concepto de descentralización y algunas sugerencias para su abordaje. Disponível em: <http://www.iuperj.br/publicacoes/forum/ textos/alicia.htm> Acesso em: 10 jul. 2003.

VOSS, Dulce Mari da Silva. O Plano de Desenvolvimento da Educação (PDE): contexto e discursos. Cadernos de Educação, Pelotas, n. 38, p. 43-67, jan.-abr. 2011.
WERLE, Flávia Obino Corrêa. A reinvenção da gestão dos sistemas de ensino: uma discussão do Plano de Desenvolvimento da Educação (2007). Revista Educação em Questão, Natal, v. 35, p. 98-119, maio-ago., 2009.

\section{Notas}

${ }^{1}$ Em outras palavras, as ações que constituem o PDE não vieram a ser discutidas no âmbito do poder legislativo federal, tampouco junto à sociedade civil (CAMARGO; PINTO; GUIMARÃES, 2008; CURY, 2007; FARENZENA; LUCE, 2007; PONTUAL, 2007), embora, contraditoriamente, defenda a importância da participação social na formulação, no monitoramento da execução e na sua avaliação (RAMOS, 2007).

2 A Aneb é realizada por amostragem das Redes de Ensino, em cada unidade da Federação, com foco na gestão dos sistemas educacionais. "Por manter as mesmas características, a Aneb recebe o nome do Saeb em suas divulgações". Disponível em: $<$ http://gestao2010.mec.gov.br/o que foi feito/program 77.php>. Acesso em: 21 fev. 2013.

3 Também denominada de Saeb, a Anresc se trata de um processo avaliativo baseado em amostras "que visa apresentar também resultados de desempenho em Língua Portuguesa e Matemática por Estado, região e país, localização (urbana/rural), dependência administrativa (redes municipal, estadual, federal e particular), além de outros estratos de interesse". Disponível em: <http://gestao2010.mec.gov.br/o_que_foi feito/program_77.php>. Acesso em: 21 fev. 2013.

4 Disponível em: $<$ http://simec.mec.gov.br/cte/relatoriopublico/principal. php>. Acesso em: 10 jan. 2013.

5 Em relação ao Município de Cambuci, consta o aviso de que ele havia iniciado a elaboração do seu PAR, porém, ainda não o havia concluído e enviado "para análise do MEC". No que tange ao Município de Nova Iguaçu, vale esclarecer que este Município já tinha elaborado seu PAR, o qual, aliás, se destacava pelas pontuações negativas dadas aos seus indicadores (ALCÂNTARA, 2011), e que esses dados permaneceram disponíveis no site do Simec até meados do ano de 2010, quando passou a constar o aviso de que o Município iniciara a elaboração do PAR. Atualmente, é indicado que o Município de Nova Iguaçu já o concluiu, e que "o MEC está realizando sua análise técnica". Portanto, em relação a este Município, não há, no momento, PAR disponível para análise.

6 Disponível em: <http://g1.globo.com/rio-de-janeiro/noticia/2012/08/ ideb-do-rj-fica-acima-do-projetado-pelo-mec-para-2011.html>. Acesso em 20 jun. 2014.

7 Disponível em: $<$ http://simec.mec.gov.br/cte/relatoriopublico/principal. php>. Acesso em: 10 jan. 2013.

8 Id.

Artigo recebido em janeiro 2014

Aprovado em junho 2014. 